\title{
The impact of adverse childhood experiences and recent life events on anxiety and quality of life in university students
}

\author{
Emma Davies ${ }^{1} \cdot$ John Read $^{2}$ (D) $\cdot$ Mark Shevlin $^{3}$ \\ Accepted: 1 October 2021 / Published online: 1 December 2021 \\ (c) The Author(s), under exclusive licence to Springer Nature B.V. 2021
}

\begin{abstract}
Adverse childhood experiences (ACEs) have been repeatedly associated with a wide range of physical and mental health issues. Research has indicated high levels of anxiety and depression among university students, and a few studies have documented the relationship between ACEs and anxiety in the university student population. This study surveyed first year students at a university located in the most ethnically diverse district in England, with the second highest poverty rate. Eight hundred and fifty-eight responded; a response rate of $12 \%$. The survey included questions about adverse childhood events, recent life stressors, current deprivation, quality of life, positive physical health and positive mental health, and used the Generalized Anxiety Disorder Scale, a standardised measure. Thirty-seven percent of the responding students met the diagnosis for generalised anxiety disorder. In a multivariate multiple regression model, life stressors and childhood adversities were significantly associated with higher levels of anxiety and lower levels of physical and mental health. Only childhood adversities significantly predicted lower levels of quality of life. The findings highlight the importance of considering adverse childhood experiences in enhancing the wellbeing of the student population. Given the demographics of the student population at the University of East London, the high rates of ACEs and anxiety are likely to partially reflect poverty and racism. The implications of the findings for traumainformed policies and practices in universities are discussed.
\end{abstract}

Keywords Adverse childhood experiences (ACEs) · University students · Poverty · Racism $\cdot$ Anxiety $\cdot$ Quality of life

John Read

john@uel.ac.uk

Emma Davies

e.davies@uel.ac.uk

Mark Shevlin

m.shevlin@ulster.ac.uk

1 School of Business and Law, University of East London, Water Lane, London E15 4LZ, UK

2 School of Psychology, University of East London, Water Lane, London E15 4LZ, UK

3 School of Psychology, Ulster University, Coleraine Campus, Cromore Road, Corelaine, Co., Londonderry BT52 1SA, UK 


\section{Introduction}

Adverse childhood experiences (ACEs) have been repeatedly associated with a wide range of physical and mental health issues (Bellis et al., 2014; Felitti et al., 1998; Merrick et al., 2017). For example, the long-term physical effects of abuse and neglect include higher rates of cancer, strokes, arthritis, diabetes, lung disease, heart attacks, high blood pressure and bowel disease (Afifi et al., 2016; Monnat \& Chandler, 2015; Widom et al., 2012). The long-term mental health impacts of child abuse and neglect include anxiety, depression, PTSD, eating difficulties, 'personality disorders', dissociation, sexual difficulties, substance abuse, psychosis and mood swings (Arnekrans et al., 2018; Cromby et al., 2018; Kendler et al., 2000; Kessler et al., 2010; Varese et al., 2012). In a general population study in the USA, those reporting at least one ACE experienced significantly lower levels of life satisfaction than those who did not, after controlling for demographic variables (MosleyJohnson et al., 2019).

There are a few studies documenting the extent and impact of childhood adversities in university students. One study, of 2637 undergraduate students in the USA, found that 16.3\% reported multiple childhood adversities (Berzenski \& Yates, 2011). Berzenski and Yates (2011) found that emotional abuse, alone or in combination with other types of child abuse and neglect, was especially salient for anxiety and depression. A US study of 311 female undergraduates found that $29.6 \%$ reported at least one of the four types of child maltreatment assessed; $97.4 \%$ had experienced at least one of the 34 specific types of childhood victimisation, across six categories; and $15.4 \%$ reported at least one type of child maltreatment from all six categories. Poly-victimisation was significantly related to current psychological distress in this study (Richmond et al., 2009) and in a more recent US study of 349 college students (Elliott et al., 2019).

Myers et al. (2021) conducted a web-based survey of 1260 first year students from two large urban universities in South Africa. Forty-eight percent reported one or more types of childhood maltreatment, the most common being emotional abuse $(26.7 \%)$ and physical abuse (20.8\%). These two types of abuse were particularly predictive of current depression, anxiety and drug use.

When 765 students completed the Adverse Childhood Experiences (ACEs) questionnaire at Queen's University in Belfast, 56\% reported at least one of the ten adversities and 12.4\% reported four or more (McGavock \& Spratt, 2014).

It is established that the prevalence of anxiety, depression and stress is high among undergraduate university students (Mofatteh, 2020; Storrie et al., 2010). Furthermore, studies in the USA and Northern Ireland have found that female students, those over 21, financially poorer students and non-heterosexual students experience more mental health problems (Eisenberg et al., 2007; McLafferty et al., 2017).

As in the general population, adverse childhood experiences are important contributors to the development of these mental health issues in university students (Karatekin, 2018). More recent adverse life events also impact the mental and physical health of university students. Those who reported more negative life events experienced poorer mental health and educational outcomes (Anders et al., 2012). There is also emerging evidence that those who have experienced adverse childhood experiences are more susceptible to stress in the Covid-19 pandemic (Xiaojing et al., 2021).

University students who have experienced traumatic events are more likely to feel anxious and lonely at university (Kearney et al., 2018; McIntyre et al., 2018), which can impede academic success (Auamnoy et al., 2018; McIntyre et al., 2018). Students' 
experiences of more recent traumatic events also correlate directly with poor retention and low grades at university (Warnecke \& Lewine, 2019) and have been identified as barriers to academic success (Arria et al., 2020).

\section{University context}

The University of East London, formerly North East London Polytechnic, became a university in 1992. Universities in England are obliged by the Government's Office for Students to produce an Access and Participation plan which specifies how they will widen participation of underrepresented groups, the targets they have set and the investment they are making. The Office for Students monitors implementation of these plans. This project is part of the University of East London's actions to improve engagement and success of marginalised students under its Access and Participation Plan 2020-2025, including its focus on reducing the attainment gap for students from underrepresented groups and enhancing mental health as a key component of student success (University of East London, 2020).

\section{The current study}

The current study represents the first stage of a project at the University of East London, 'Beyond Adversity', designed to enhance student wellbeing, retention and achievement via the development of a strategy addressing the multiple adversities experienced by students.

An earlier paper emanating from the Beyond Adversity programme reported some of the results of the survey of first year undergraduates, concerning childhood adversities. The majority, $79 \%$, reported one or more adverse events; $51 \%$ reported three or more; and $20 \%$ six or more. Women reported more adversities than men, but men were more likely to report having been 'attacked, stabbed, shot or robbed by threat'. Rates tended to be higher than in the general population or at another UK university survey (McGavock \& Spratt, 2014). A Latent Class Analysis produced four groupings: 'no adversity' (36\%); 'intermediate' (46\%); moderate (6\%) and 'high adversity' (12\%) (Davies et al., 2021).

The primary aim of the current paper was to assess whether current life stressors and adverse childhood experiences are associated with a range of wellbeing outcomes in a large sample of university students who participated in the Beyond Adversity research project. Thus, the study was grounded in psycho-social theories of mental health, within which a range of adversities, and our responses thereto, are seen as primary in the aetiology of emotional distress and disturbance (Cromby et al., 2018; Johnstone et al., 2018; Read \& Sanders, 2010; Read \& Dillon, 2013). This is consistent with the 'trauma-informed' paradigm gradually being adopted within mental health and other services and institutions (SAMHSA, 2014; Scottish Government, 2021; Sweeney et al., 2016).

The outcomes included scores on a standardised measure of generalised anxiety disorder (GAD-7) and self-reported levels of quality of life, positive physical health and positive mental health. It was predicted that higher levels of life stressors and adverse childhood experiences would be associated with higher levels of generalised anxiety disorder and lower levels of quality of life, positive physical health and positive mental health. It was expected that these associations would be significant after controlling for demographic 
variables (age, gender, ethnicity, childcare responsibilities) and deprivation (using the index of multiple deprivation).

\section{Materials and methods}

The project was approved by the University of East London (UEL) Research Ethics Committee. Informed consent was given by all participants at the beginning of the questionnaire.

\section{Participants}

All 7825 first year (level 4) undergraduate students, at least 18 years of age, were eligible to participate. UEL is situated in the London Borough of Newham, which, at the 2011 census, was the most ethnically diverse district in England and Wales. It has the second highest poverty rate in the country (Trust for London, 2017). Just over three quarters of UEL students are from this local area.

\section{The survey}

The Beyond Adversity survey was designed for this project. It was piloted with eight students. It consists of questions about childhood adversities, adult adversities, stressors and caring/parenting responsibilities, and a range of outcome measures, including quality of life and anxiety. This data was matched with demographic data from UEL's Strategic Planning Department through student IDs. The questions that are the focus of the current paper are the questions about anxiety, quality of life, mental health, physical health, stressors in the last 6 months and adverse child experiences.

\section{Childhood adversities}

There were nine questions from the Adverse Childhood Experiences (ACEs) scale (Felitti et al., 1998) about abuse, neglect and parental mental illness, incarceration, substance use, separation and domestic violence. These questions were preceded by the statement 'While you were growing up, before the age of 18 ...' In response to feedback from the pilot study, an additional response option was added to the question about separation and divorce, to include the response that parents never lived together. The three additional questions were as follows: 'Have you been threatened, hit or hurt badly in school or the community?' 'Have you been attacked, stabbed, shot at or robbed by threat?' and 'Have you been treated badly because of race, sexual orientation, place of birth, disability or religion?' These additional questions about violence were taken from the CATS Life Events screen (version 2.0) in an attempt to ensure a more comprehensive coverage of childhood adversities. The discrimination question was added mindful of the demographics of our student body.

Most questions required yes/no responses. The abuse and neglect questions included 'once' and 'more than once' options. These two options were combined to form a positive 
response for the purposes of data analysis, except for the verbal/emotional abuse question ('Did a parent or adult in your home ever swear at you, insult you, or put you down?') for which only the 'more than once' response counted as a positive response, partly so as to be comparable to a general population study (Bellis et al., 2014). There were three possible responses to 'Were your parents ever separated or divorced?': 'No', 'Yes' and 'Parents didn't live together'. Either of the last two responses was scored as one positive response when calculating total adversities.

\section{Generalised anxiety}

Symptoms of generalized anxiety were assessed using the Generalized Anxiety Disorder Scale (GAD-7: Spitzer et al., 2006). Respondents were asked to report 'Over the last 2 weeks, how often have you been bothered by...' seven anxiety symptoms (e.g. 'trouble relaxing', 'becoming easily annoyed or irritable'). Response options were 'Not at all', 'Several days', 'More than half the days' and 'Nearly every day', scored as 0, 1, 2 and 3, respectively. GAD-7 scores range from 0 to 21 with higher scores indicating higher levels of anxiety. A cut-off score of 10 was used, and this has been shown to result in a sensitivity of $89 \%$ and a specificity of $82 \%$ (Spitzer et al., 2006). The GAD-7 has good reliability and construct validity, as evidenced by strong associations with other established measures of anxiety as well as the diagnosis of generalised anxiety disorder and its associations with depression, self-esteem, life satisfaction and resilience (Löwe et al., 2008).

\section{Quality of Life, Physical and Mental Health}

Participants were asked to rate their perceived 'quality of life', 'physical health' and 'mental health' each on a scale from (1) 'worst I can imagine' to (7) 'best I can imagine'.

\section{Stressful life events}

The total number of stressful life events was measured using the stressor list from the Adjustment Disorder - New Module (ADNM-20: Einsle et al., 2010). The stressor list consists of 16 potentially stressful events (e.g. divorce/separation, conflicts in work life, unemployment, moving to a new home), and participants were provided with these instructions: 'Below is a list of stressful life events that may affect our wellbeing and behaviour. Please indicate those events that happened in the last year and are currently a strong burden to you or have been a strong burden to you in the last six months'. Responses were coded (1) yes and $(0)$ no, and the scores were summed to produce an overall score ranging from 0 to 16.

\section{Deprivation}

The UK index of multiple deprivation [IMD] 2019 deciles were coded for each participant based on their 'lower-layer super output area' derived from their registered address. Deciles were used, with lower values indicating higher levels of deprivation. 


\section{Recruitment}

The survey was completed on the UEL-supported online survey platform with a link through student email addresses. Seven part-time student interns were employed to assist with additional recruitment. They received training on ethics and confidentiality from the first author and training with a mental health practitioner to enable them to respond to issues that may come up for participants. Programme and module leaders were asked to give the interns brief access to lectures and tutorials. The interns then explained the project and asked for participation either immediately, if the lecturer had agreed, or at some time after the lecture.

The participant information made it clear that only the researchers could access their responses, that demographic data would be accessed through UEL and that accepting the offer to participate or choosing to decline would have no impact on students' assessments or learning experience. Throughout the survey, all participants were repeatedly offered access to trauma-informed student wellbeing services, which had been extended for this purpose in case some students were triggered by responding to the survey. To the best of our knowledge none were triggered.

\section{Data analysis}

The analyses were carried out in two phases. First, descriptive statistics and bivariate correlations were calculated for all variables. The categorical variable of ethnicity (black, Asian, white, other/missing) was dummy coded into two variables representing black and Asian (both compared to white category). Pearson product moment correlations were calculated for all continuous variables and point-biserial for the binary-continuous variables. Second, in order to estimate the degree to which the demographic and trauma variables predicted the mental health variables, a multivariate multiple regression model was specified and estimated using Mplus 8.2 (Muthén \& Muthén, 2017). The outcome variables were anxiety (GAD) and scores on the questions on quality of life, physical health and mental health, and these were all simultaneously regressed on the predictor variables of age, gender (male), ethnicity (black, Asian), children (no/yes), deprivation decile, total stressors and total ACEs. The parameters were estimated using robust maximum likelihood, and the results are presented as standardised regression coefficients.

\section{Results}

\section{Sample characteristics}

The survey was completed by 858 of the 7110 first year students, a response rate of $12.1 \%$. More than two thirds $(69.3 \%)$ were women. Nearly a third $(30.0 \%)$ were categorised as 'black', 28.9\% as 'white' and $22.0 \%$ as 'Asian' (plus 19.2\% as either 'other' or 'unknown'). The average age was 27.7 years $(\mathrm{sd}=13.5)$. Black students were significantly older (mean $=32.9$ years) than both white (27.6) and Asian students (23.2), and white students were significantly older than Asian students (all differences at the $p<0.001$ level). $42.8 \%$ were from the three most deprived IMD deciles, with $56.9 \%$ from the poorest four deciles. The mean IMD decile of the Asian students (3.0) was higher (more deprived) than those 


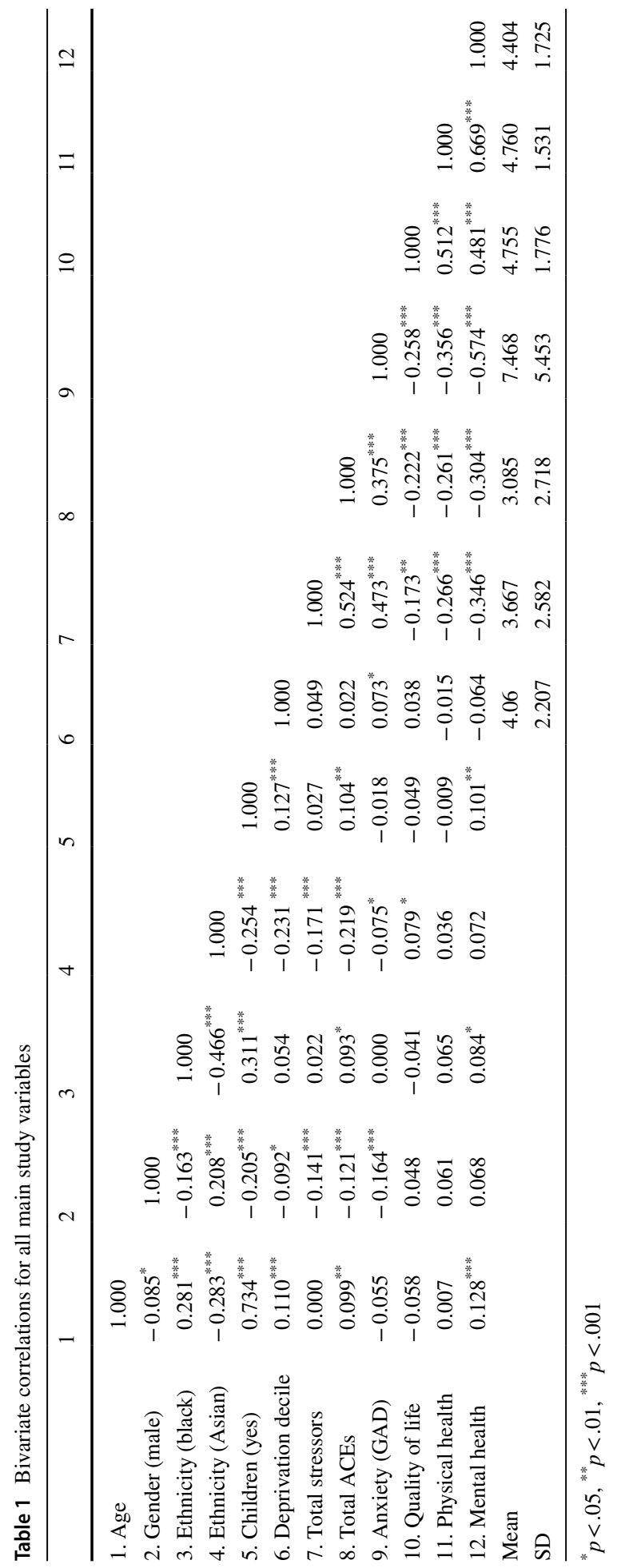


of both the black $(3.7 ; p<0.005)$ and white $(4.1 ; p<0.001)$ students, with the latter two groups not differing significantly from each other.

The demographics of the students from which this sample emanated was $54.6 \%$ female, $25.8 \%$ 'black', 38.3\% 'Asian', 24.2\% 'white' and 11.7\% 'other'/' unknown', with an average age of 29.2 years. Just over half $(53.8 \%)$ of all first year students were from the three most deprived IMD deciles, with $70.7 \%$ from the poorest four deciles. Thus, male and Asian students, and those living in the more deprived neighbourhoods, were underrepresented in our sample.

Table 1 shows the descriptive statistics and correlations for the main study variables.

The mean index of multiple deprivation decile was 4.06, confirming that many of the participants lived in areas with higher-than-average levels of deprivation. On average, the participants reported 3.7 stressors and 3.1 childhood adversities, and these were significantly associated $(r=0.524, p<0.001)$. The mean GAD-7 score was 7.5 , with $37.1 \%$ of the samples exceeding the cut-off score to indicate clinically meaningful levels of anxiety. The mean levels of quality of life (4.8), physical health (4.8) and mental health (4.4) were just above the theoretical mean of the 1-7 scale. Higher levels of life stressors were associated with higher levels of anxiety $(r=0.47, p<0.001)$ and lower levels of quality of life $(r=-0.17, p<0.01)$, physical health $(r=-0.27, p<0.001)$ and mental health $(r=-0.35$, $p<0.001)$. Higher levels of childhood adversities were associated with higher levels of anxiety $(r=0.37, p<0.001)$ and lower levels of quality of life $(r=-0.22, p<0.01)$, physical health $(r=-0.26, p<0.001)$ and mental health $(r=-0.30, p<0.001)$.

Table 2 shows the standardised regression coefficients for the regression model.

A significant proportion of variance ( $R$-squared) in each of the dependent variables was explained, with anxiety being the variable with the most variance explained. Life stressors and childhood adversities were significantly associated with higher levels of anxiety, and lower levels of physical and mental health. Only childhood adversities significantly predicted lower levels of quality of life.

Table 2 Standardised regression coefficients from the regression model predicting anxiety, quality of life and physical and mental health

\begin{tabular}{lllcc}
\hline Predictor & Anxiety & Quality of life & Physical health & Mental health \\
\hline Age & -0.064 & -0.041 & 0.018 & $0.115^{*}$ \\
Gender (male) & $-0.103^{* *}$ & 0.013 & 0.027 & 0.029 \\
Ethnicity (black) & -0.003 & -0.001 & 0.093 & $0.098^{*}$ \\
Ethnicity (Asian) & 0.040 & 0.028 & 0.006 & 0.060 \\
Children & -0.018 & 0.003 & -0.021 & 0.040 \\
Deprivation decile & $0.060^{*}$ & 0.057 & -0.003 & -0.055 \\
Total stressors & $0.364^{* * *}$ & -0.080 & $-0.171^{* * *}$ & $-0.234^{* * *}$ \\
Total ACEs & $0.188^{* * *}$ & $-0.169^{* * *}$ & $-0.174^{* * *}$ & $-0.188^{* * *}$ \\
$R$-squared & $0.265^{* * *}$ & $0.059^{* *}$ & $0.099^{* * *}$ & $0.175^{* * *}$ \\
\hline
\end{tabular}

${ }^{*} p<.05,{ }^{* *} p<.01,{ }^{* * *} p<.001$ 


\section{Discussion}

This study documents a strong correlation between adverse childhood experiences and a range of measures of wellbeing in a large sample of university students, including high levels of anxiety and poor quality of life. The first article from the Beyond Adversity project documented the large numbers of university students who have survived adverse childhood experiences (Davies et al., 2021). Females and black students reported more adversities and discrimination than other groups. Race and gender can intersect to amplify experiences of disadvantage and discrimination, so female black students may experience more oppression than either white females or black males (Crenshaw, 1989). Female students reported more adversities, including sexual abuse, than male students. These results suggest the social factors that may contribute to differences between groups, including racism (Paradies et al., 2015; Shonkoff et al., 2021), sexism (Klonoff et al., 2000; Warner, 2017) and the intersection between the two (Crenshaw, 1989).

Where precise comparisons could be made with the general population or other universities, the UEL sample had higher rates of childhood adversities, particularly for sexual abuse, verbal/emotional abuse and living with domestic violence in childhood (Davies et al., 2021). These differences are consistent with previous findings that ACE scores are highly correlated with poverty (Nurius et al., 2016) and deprived geographical areas (Lewer et al., 2019), where most of UEL's students live.

On the GAD-7, 37\% met the diagnostic criteria for generalised anxiety disorder. This is significantly higher than the $17.5 \%$ found in a comparable Australian survey of university undergraduate students (Farrer et al., 2016). In both studies, the GAD was higher for female students. Likewise, the UEL GAD data is higher than the $22.6 \%$ found in a large sample of university entrance students in Northern Ireland (McLafferty et al., 2017). Both of these studies found that students experiencing financial stress were more likely to reach the threshold for GAD (Farrer et al., 2016; McLafferty et al, 2017). As most of this sample, and UEL's students, live in areas of relatively high deprivation, poverty may partially account for the higher rates in this sample.

While financial stressors are important, the findings of this study confirm that some of the root causes of anxiety and poor mental and physical wellbeing and quality of life at university are adverse childhood experiences. This is consistent with the findings in the World Mental Health Survey involving 21 countries, in which most onset of mental health problems occurred prior to commencing university (Auerbach et al., 2016).

\section{Implications}

Prior to this study, there was less understanding of the prevalence of adverse childhood experiences within the UEL student population, and of the relationship between adverse child experiences, student's current levels of anxiety and self-reported quality of life. Active dissemination and discussion of the findings with students and staff is already increasing the visibility of these issues within the institution. These analyses informed a one-day staff training on trauma-informed care and educational practices, attended by 200 staff members, as well as structured discussions with staff and students in 2021.

Because of the causal role of trauma and adversity in most mental health problems, trauma-informed services are gradually being introduced into mental health care systems (Read et al., 2018; SAMHSA, 2014; Sweeney et al., 2016). A trauma-informed 
environment is based on principles of safety (emotional and physical), trusting relationships, choice and collaboration (Scottish Government, 2021). Planned, structured discussions with students and staff will reflect on these principles in relation to a wide range of policies and practice within the university in order to create an action plan.

Consideration will be given to the support of, and ongoing in-service training for, staff, to equip them to empower and support students. Academics are part of the student support systems (Brown, 2018). They spend considerable time offering pastoral care to students who are struggling academically. More often than not, academic challenges stem from the personal and social issues outlined in this paper. It has been argued that universities need to clarify the role of personal tutors/academic advisors in mental health, and support and train staff to perform this role (Hughes et al., 2018). Academics need sufficient time in workload models for pastoral care and for the training to include trauma-informed practice and active listening skills.

The planned structured discussions with students and staff will also consider how admissions and induction processes can be enhanced to engender trust and empower students to create a sense of belonging from the start of their University experience. They will also discuss how to enhance extenuation processes for extensions to assignment deadlines to reduce stress on students and increase clarity and transparency in the processes.

The University of East London is trying to actively teach emotional and social development in preparation for employment in modules from level 3 (pre-degree) to level 7 (master's degree). The data from this project highlights the vulnerabilities of undergraduate students which renders this instruction potentially very helpful (Brown, 2018). However, this well-intentioned initiative also has the potential to be harmful if done without due cognizance of the long-standing issues that many students face. One risk is that students might be inadvertently triggered without sufficient support to manage these emotions. This is being discussed in staff training sessions, with increasing emphasis on enabling students to choose what they participate in, and on skill building. There is emerging evidence that teaching meditation techniques in universities can help some students to manage anxiety (Carpena et al., 2019) and that mindfulness practice can mediate the relationship between trauma and anxiety (Tubbs et al., 2019). Social skills training can also help some students to develop friendships, reduce anxiety and support wellbeing (Moellera \& Seehuus, 2019).

Given the importance of peer support to mental wellbeing (Brown, 2018), UEL already has a number of peer support programmes, though the efficacy of some of them is unclear. A trauma-informed lens could enhance the training of peer mentors to include traumainformed practices.

While some students will flourish with informal support, others will need more specialised interventions. It has been argued that the quality and quantity of wellbeing services in the university sector need to be improved, with more flexible opening hours (Holm-Hadulla \& Koutsoukou-Argyraki, 2015) and increased awareness of the impact of child maltreatment on wellbeing (Myers et al., 2021). These services need trained staff who understand the impact of trauma (Anders et al., 2012). Trauma-Informed Cognitive Behavioural Therapy and Eye Movement Desensitisation Therapy are among the most promising interventions according to guidelines such as those published by the United Kingdom's National Institute of Health and Clinical Excellence (NICE). While online counselling services may help to keep up with demand (Mofatteh, 2020), effective therapeutic interventions require skilled staff whether online or face to face, and universities struggle to find the resources to employ them. Given that many of UEL's students are parents, effective therapeutic interventions may also benefit the next generation as caregivers 
being exposed to four or more ACEs triples the odds of their children experiencing anxiety or depression later in the lifespan (Haynes et al., 2020).

Finally, by assessing the various dimensions of policy and practice through a traumainformed lens, it will be important to balance institutional needs and efficient processes with an awareness that enabling marginalised students to flourish requires quality relationships that take time.

\section{Limitations}

The response rate of $12.1 \%$ was lower than the $18.6 \%$ achieved by another UK study of undergraduates (McGavock \& Spratt, 2014). The response rate raises concerns about generalizability to the 7110 first year students as a whole. For example, students with higher rates of adversities may have been more likely to be non-responders because remembering and reporting the adversities might cause discomfort. Another possible source of underestimation of adversity rates is the fact that longitudinal follow-up studies of adults whose childhood abuse was documented find that their retrospective reports of childhood abuse underestimate actual occurrence (Della Femina et al., 1990; Pereda et al., 2009).In addition, there was an error in using a negative in 'parents didn't live together' which may have caused some confusion for some participants. Failure to include a physical abuse item, and gender in the discrimination item, were oversights on our part that almost definitely lowered the total adversity scores.

Supplementary Information The online version contains supplementary material available at https://doi. org/10.1007/s10734-021-00774-9.

Acknowledgements We would like to thank the multi-disciplinary Beyond Adversity Advisory Group, drawn from various components of the University of East London: Natalie Freeman (volunteering manager), Dr. Eva Galante (bioscience), Dr. Rawad Hammad (computing), Mohammad Ismail (student union president), Gail May (director of civic engagement), John McCarthy (head of student wellbeing services), Dr. Rebecca Page-Tickell (business and law), Dr. Elizabeth Stokes (business and law) and Dr. Angie Voela (social sciences).

The project could not have succeeded without the enthusiasm and hard work of the student interns: Halima Sacdia Abdirahman, Khalid Fata, Sophie Fletcher, Rozina Iqbal, Aliyah Jeewa, Chloe Mzimba and Nangyaly Shinwari.

Funding Funding was provided through a competitive process within UEL for Office for Students funding under UEL's Access and Participation Plan.

\section{Declarations}

Conflict of interest The authors declare no conflicts of interest.

\section{References}

Afifi, T., MacMillan, H., Boyle, M., Cheung, K., Taillieu, T., Turner, S., \& Sareen, J. (2016). Child abuse and physical health in adulthood. Health Reports, 27, 10-18.

Anders, S. L., Frazier, P. A., \& Shallcross, S. L. (2012). Prevalence and effects of life event exposure among undergraduate and community college students. Journal of Counseling Psychology, 59, 449-457.

Arnekrans, A. K., Calmes, S. A., Laux, J. M., Roseman, C. P., Piazza, N. J., Reynolds, J. L., Harmening, D., \& Scott, H. L. (2018). College students' experiences of childhood developmental traumatic stress: 
Resilience, first-year academic performance, and substance use. Journal of College Counseling, 21(1), $2-14$.

Arria, A. M., Barrall, A. L., Vincent, K. B., Bugbee, B. A., \& O’Grady, K. E. (2020). Development of the measure of obstacles to succeeding academically in college (MOSAIC). Journal of College Student Development, 61(1), 103-108.

Auamnoy, T., Anothayanon, C., Limyoosawas, N., Thanathumjaree, J., \& Chaisuwannarak, P. (2018). PMH22 - Anxiety test predicted academic achievement in pharmacy students at Burapha University. Value in Health, 21(2), S77.

Auerbach, R., Alonso, J., Axinn, W., Cuijpers, P., Ebert, D., Green, J., \& Bruffaerts, R. (2016). Mental disorders among college students in the World Health Organization World Mental Health Surveys. Psychological Medicine, 46(14), 2955-2970. https://doi.org/10.1017/S0033291716001665

Bellis, M., Lowey, H., Leckenby, N., Hughes, K., \& Harrison, D. (2014). Adverse childhood experiences: Retrospective study to determine their impact on adult health behaviours and health outcomes in a UK population. Journal of Public Health, 36, 81-91.

Berzenski, S., \& Yates, T. (2011). Classes and consequences of multiple maltreatment: A person-centered analysis. Child Maltreatment, 16, 250-261.

Brown, J. (2018). Student mental health: Some answers and more questions. Journal of Mental Health, 27, 193-196.

Carpena, M. X., de Souza Tavares, P., \& Menezes, C. B. (2019). The effect of a six-week focused meditation training on depression and anxiety symptoms in Brazilian university students with 6 and 12 months of follow-up. Journal of Affective Disorders, 246, 401-407.

Crenshaw, K. (1989). Demarginalizing the intersection of race and sex: A black feminist critique of antidiscrimination doctrine, feminist theory and antiracist policies. University of Chicago Legal Forum, $1,139-167$.

Cromby, J., Harper, D., \& Reavey, P. (2018). Psychology, mental health and distress. Palgrave MacMillan.

Davies, E., Read, J., \& Shevlin, M. (2021). Childhood adversities among students at an English University: a latent class analysis. Journal of Trauma and Dissociation. https://doi.org/10.1080/15299732. 2021.1987373.

Della Femina, D., Yeager, C., \& Lewis, D. (1990). Child abuse: Adolescent records vs. adult recall. Child Abuse \& Neglect, 14, 227-231.

Elliott, A. N., Faires, A., Turk, R. K., Wagner, L. C., Pomeroy, B. M., Pierce, T. W., \& Aspelmeier, J. E. (2019). Polyvictimization, psychological distress, and trauma symptoms in college men and women. Journal of College Counseling, 22(2), 138-151.

Einsle, F., Köllner, V., Dannemann, S., \& Maercker, A. (2010). Development and validation of a selfreport for the assessment of adjustment disorders. Psychology, Health and Medicine., 15(5), 584595. https://doi.org/10.1080/13548506.2010.487107 PMID: 20835968.

Eisenberg, D., Gollust, S. E., Golberstein, E., \& Hefner, J. L. (2007). Prevalence and correlates of depression, anxiety, and suicidality among university students. The American Journal of Orthopsychiatry, 77, 534-542.

Farrer, L. M., Gulliver, A., Bennett, K., Fassnacht, D. B., \& Griffiths, K. M. (2016). Demographic and psychosocial predictors of major depression and generalised anxiety disorder in Australian university students. BMC Psychiatry, 16, 241-249.

Felitti, V., Anda, R., Nordenburg, D., Williamson, D., Spitz, A., Edwards, V., Koss, M., \& Marks, J. (1998). Relationship of childhood abuse and household dysfunction to many of the leading causes of death in adults: The Adverse Childhood Experiences (ACE) study. American Journal of Preventive Medicine, 14, 245-258.

Haynes, E., Crouch, E., Probst, E., Radcliff, E., Bennett, K., \& Glover, S. (2020). Exploring the association between a parent's exposure to adverse childhood experiences (ACEs) and outcomes of depression and anxiety among their children. Children and Youth Services Review, 113, 1-6.

Holm-Hadulla, R. M., \& Koutsoukou-Argyraki, A. (2015). Mental health of students in a globalized world: Prevalence of complaints and disorders, methods and effectivity of counseling, structure of mental health services for students. Mental Health \& Prevention., 2015, 1-4.

Hughes, G., Panjwani, M., Tulcidas, P. \& Byrom, N. (2018). Student mental health: the role and experiences of academics. London: Student Minds

Johnstone, L., Boyle, M., Cromby, J., Dillon, J., Harper, D., Kinderman, P., Longden, E., Pilgrim, D. \& Read, J. (2018). The power threat meaning framework: towards the identification of patterns in emotional distress, unusual experiences and troubled or troubling behaviour, as an alternative to functional psychiatric diagnosis. Leicester: British Psychological Society 
Karatekin, C. (2018). Adverse childhood experiences (ACEs), stress and mental health in college students. Stress and Health, 34, 36-45.

Kearney, M. A., Zeligman, M., Brack, J. L., \& Payne, E. (2018). Trauma and dissociation: Predictors of loneliness in students at an urban university. Journal of College Counseling, 21(2), 165-179.

Kendler, K., Bulik, S., Silberg, J., Hettema, J., Myers, J., \& Prescott, C. (2000). Childhood sexual abuse and adult psychiatric and substance use disorders in women. Archives of General Psychiatry, 57, 953-959.

Kessler, R., McLaughlin, K., Green, J., Gruber, M., Sampson, N., Zaslavsky, A., Aguilar-Gaxiola, S., Obaid Alhamzawi, O., Alonso, J., Angermeyer, M., Benjet, C., Bromet, E., Chatterji, S., De Girolamo, G., Demyttenaere, K., Fayyad, J., Florescu, S., Gal, G., Gureje, O., ... Williams, D. (2010). Childhood adversities and adult psychopathology in the WHO world mental health surveys. British Journal of Psychiatry, 197, 378-385.

Klonoff, E. A., Landrine, H., \& Campbell, R. (2000). Sexist discrimination may account for well-known gender differences in psychiatric symptoms. Psychology of Women Quarterly, 24(1), 93-99.

Lewer, D., King, E., Bramley, G., Fitzpatrick, S., Treanor, M. C., Maguire, N., Bullock, M., Hayward, A., \& Story, A. (2019). The ACE Index: Mapping childhood adversity in England. Journal of Public Health, 42, 487-495.

Löwe, B., Decker, O., Müller, S., Brähler, E., Schellberg, D., Herzog, W., \& Herzberg, P. Y. (2008). Validation and standardization of the Generalized Anxiety Disorder Screener (GAD-7) in the general population. Medical Care, 46(3), 266-274. https://doi.org/10.1097/MLR.0b013e318160d093

McGavock, L., \& Spratt, T. (2014). Prevalence of adverse childhood experiences in a university population: Association with use of social services. British Journal of Social Work, 44, 657-674.

McIntyre, J. C., Worsley, J., Corcoran, R., Woods, P. H., \& Bentall, R. P. (2018). Academic and nonacademic predictors of student psychological distress: The role of social identity and loneliness. Journal of Mental Health, 27, 230-239.

McLafferty, M., Lapsley, C. R., Ennis, E., Armour, C., Murphy, S., Bunting, B. P., et al. (2017). Mental health, behavioural problems and treatment seeking among students commencing university in Northern Ireland. PLoS ONE, 12(12), e0188785. https://doi.org/10.1371/journal.pone.0188785

Merrick, M., Ports, K. A., Forda, D. C., Afifib, T., Gershoff, E. T., \& Grogan-Kaylor, A. (2017). Unpacking the impact of adverse childhood experiences on adult mental health. Child Abuse \& Neglect, 16, 10-19.

Moellera, R. W., \& Seehuus, M. (2019). Loneliness as a mediator for college students' social skills and experiences of depression and anxiety. Journal of Adolescence, 73, 1-13.

Monnat, S., \& Chandler, R. (2015). Long-term physical health consequences of adverse childhood experiences. The Sociological Quarterly, 56, 723-752.

Mofatteh, M. (2020). Risk factors associated with stress, anxiety, and depression among university undergraduate students. AIMS Public Health, 8, 36-65.

Mosley-Johnson, E., Garacci, E., Wagner, N., Mendez, C., Williams, J. S., \& Egede, L. E. (2019). Assessing the relationship between adverse childhood experiences and life satisfaction, psychological well-being, and social well-being: United States Longitudinal Cohort 1995-2014. Quality of Life Research., 28(4), 907-914.

Muthén, L. K., \& Muthén, B. O. (2017). Mplus: statistical analysis with latent variables: user's guide (Version 8). Los Angeles, CA: Authors.

Myers, B., Bantjes, J., Lochner, C., Mortier, P., Kessler, R., \& Stein, D. (2021). Maltreatment during childhood and risk for common mental disorders among first year university students in South Africa. Social Psychiatry and Psychiatric Epidemiology. https://doi.org/10.1007/ s00127-020-01992-9

Nurius, P., Green, S., Logan-Greene, P., Longhi, D., \& Song, C. (2016). Stress pathways to health inequalities: Embedding ACEs within social and behavioural contexts. International Public Health Journal, 8, 241-256.

Paradies, Y., Ben, J., Denson, N., Elias, A., Priest, N., Pieterse, A., Gupta, A., Kelaher, M., \& Gee, G. (2015). Racism as a determinant of health: a systematic review and meta-analysis. PloS one, 10(9), e0138511.

Pereda, N., Guilera, G., Forms, M., \& Gomez-Benito, J. (2009). The prevalence of child sexual abuse in community and student samples: a meta-analysis. Clinical Psychology Review, 29, 328-338.

Read, J., \& Dillon, J. (Eds.). (2013). Models of madness: Psychological, social and biological approaches to psychosis. Routledge.

Read, J., Harper, D., Tucker, I., \& Kennedy, A. (2018). How do mental health services respond when child abuse or neglect become known? A literature review. International Journal of Mental Health Nursing, 27, 1606-1617. 
Read, J., \& Sanders, P. (2010). A straight talking introduction to the causes of mental health problems. PCCS Books.

Richmond, J., Elliott, A., Pierce, T., Aspelmeier, J., \& Alexander, A. (2009). Polyvictimization, childhood victimization, and psychological distress in college women. Child Maltreatment, 14, 127-147.

Scottish Government (2021). Trauma informed practice: a toolkit for Scotland. NHS Scotland. https:// www.gov.scot/binaries/content/documents/govscot/publications/advice-and-guidance/2021/03/ trauma-informed-practice-toolkit-scotland/documents/trauma-informed-practice-toolkit-scotland/ trauma-informed-practice-toolkit-scotland/govscot\%3Adocument/trauma-informed-practice-toolk it-scotland.pdf?forceDownload=true

Shonkoff, J., Slopen, N., \& Williams, D. R. (2021). Early childhood adversity, toxic stress, and the impacts of racism on the foundations of health. Annual Review of Public Health, 42(1), 115-134.

Spitzer, R., Kroenke, K., Williams, J., \& Löwe, B. (2006). A brief measure for assessing generalized anxiety disorder: The GAD-7. Archives of Internal Medicine., 166, 1092-1097. https://doi.org/10. 1001/archinte.166.10.1092 PMID: 16717171.

Storrie, K., Ahern, K., \& Tuckett, A. (2010). A systematic review: Students with mental health problems-a growing problem. Intational Journal of Nursing Practice, 16, 1-6.

Substance Abuse and Mental Health Services Administration. (2014). Trauma-informed care and alternatives to seclusion and restraint. Washington, DC: SAMHSA

Sweeney, A., Clement, S., Filson, B., \& Kennedy, A. (2016). Trauma-informed mental healthcare in the UK: What is it and how can we further its development? Mental Health Review, 21, 174-192.

Trust for London. (2017). Poverty and inequality data for Newham. https://www.trustforlondon.org.uk/data/ boroughs/newham-poverty-and-inequality-indicators

Tubbs, J. D., Savage, J. E., Adkins, A. E., Amstadter, A. B., \& Dick, D. M. (2019). Mindfulness moderates the relation between trauma and anxiety symptoms in college students. Journal of American College Health, 67(3), 235-245.

University of East London (2020). The University of East London Access and Participation Plan 20202025. www.uel.ac.uk/about/about-uel/governance/strategy-and-planning/access-and-participation-plan

Varese, F., Smeets, F., Drukker, M., Lieverse, R., Lataster, T., Viechtbauer, W., Read, J., van Os, J., \& Bentall, R. (2012). Childhood trauma increases the risk of psychosis: A meta-analysis of patient-control, prospective and cross-sectional cohort studies. Schizophrenia Bulletin, 38, 661-671.

Warnecke, A., \& Lewine, R. (2019). First semester academic functioning of college students: the role of stressful and traumatic life events. International Journal for the Scholarship of Teaching and Learning, 13(2).

Warner, J. (2017). The unequal toll of toxic stress: how the mental burdens of bias, trauma, and family hardship impact girls and women. Center for American Progress, https://www.americanprogress.org/issues/ women/reports/2017/11/17/443028/unequal-toll-toxic-stress/

Widom, C., Czaja, S., Bentley, T., \& Johnson, M. (2012). A prospective investigation of physical health outcomes in abused and neglected children: New findings from a 30-year follow up. American Journal of Public Health, 102, 1135-1144.

Xiaojing, L., Qiuyue, L., Tang, W., Deng, W., Zhao, L., Meng, Y., Guo, W., \& Li, T. (2021). Psychological stresses among Chinese university students during the COVID-19 epidemic: The effect of early life adversity on emotional distress. Journal of Affective Disorders, 282, 33-38.

Publisher's note Springer Nature remains neutral with regard to jurisdictional claims in published maps and institutional affiliations. 